\title{
Decoupled erosion of authigenic and detrital components in soil
}

Xuming Li ${ }^{1}$, DAVID William HedDing ${ }^{2}$, YANG CHEN ${ }^{1}$, ABRAHAM CAREL GREYLING ${ }^{2}$, LAIFENG Li ${ }^{1}$, ZIMAN WU $^{1}$, GAOJUN LI ${ }^{1,3, *}$

${ }^{1}$ MOE Key Laboratory of Surficial Geochemistry, Department of Earth and Planetary Sciences, Nanjing University, Nanjing 210023, China

${ }^{2}$ Department of Geography, University of South Africa, Pioneer Avenue, Florida 1710, South Africa

${ }^{3}$ SKLLQG, Institute of Earth Environment, Chinese Academy of Sciences, Xi'an 710061, China

Hillslope erosion is arguably one of the most important processes on the Earth's surface since it connects the operation of the lithosphere, the atmosphere, the hydrosphere, and the biosphere. It is generally assumed that erosion occurs equally throughout the soil profile so that chemical depletion of the topsoil represents the intensity of weathering and the duration of surface exposure to cosmogenic radiation reflects the rate of erosion. Based on a uranium isotope dating of soil in the Lesotho Highlands, here we show that erosion operates differentially between the detrital and authigenic components of the soil. Uranium isotope comminution ages show a soil residence time of $543 \pm 32 \mathrm{kyrs}$ for the fine silt detrital particles. In contrast, soil residence time of the authigenic phases is constrained to be $\sim 22 \pm 11$ kyrs according to the accumulation of recoiled $234 \mathrm{U}$ from the absorbed $238 \mathrm{U}$ to river water. The contrasting residence times indicates dominant erosion for authigenic components of soil. This finding implies that the intensity of weathering based on bulk soil erosion and the rate of soil erosion determined by exposure dating of coarse soil grains may be invalidated due to the preferential preservation of detrital particles. 